\title{
Mechanical Design of Step-Climbing Vehicle with Passive Linkages
}

\author{
Daisuke Chugo ${ }^{1}$, Kuniaki Kawabata², Hayato Kaetsu², Hajime Asama ${ }^{3}$ \\ and Taketoshi Mishima ${ }^{4}$ \\ ${ }^{1}$ The University of Electro-Communications \\ ${ }^{2}$ RIKEN (The Institute of Physical and Chemical Research) \\ ${ }^{3}$ The University of Tokyo, ${ }^{4}$ Saitama University \\ Japan
}

\section{Introduction}

In recent years, mobile robots are expected to perform various tasks in general environments such as nuclear power plants, large factories, welfare care facilities and hospitals. However there are narrow spaces with vertical gaps made by two horizontal floors in such environments and it is difficult for general car-like vehicles to run around there.

Generally, the mobile robots are required to have quick and efficient mobile function for effective task execution. The omni-directional mobility is useful for the tasks, especially in narrow spaces, because there is no holonomic constraint on its motion (Campion et al., 1996; Bicchi et al., 2003). Furthermore, the step overcoming function is necessary when the vehicle passes over the vertical gaps. Thus, in order to run around general environment, the vehicle $\xi$ needs to equip both of two functions. In related works, various types of omni-directional mobile systems are proposed (legged robots, ball-shaped wheel robots, crawler robots, and . so on). The legged robot (Hardarson, 1997; Endo \& Hirose, 1999) can move in all directions 들 and passes over rough terrain. However, its energy efficiency is not so good because the $\frac{c}{0}$ mechanisms tend to be complicated and the robot needs to use its actuators in order to only \& maintain its posture. The robot with ball-shaped wheels can run in all directions (Wada \& Asada, 1999), however, it cannot run on the rough grounds. The special crawler mechanism (Damoto \& Hirose, 2002) is also proposed for the omni-directional mobile robot, however, w which can climb over only small steps. Therefore, there is still a lack of well-adapted mobile of system for both narrow spaces and step climbing operation.

$\frac{0}{\pi}$ Therefore, we are developing a holonomic omni-directional vehicle with step-climbing స్ ability. (Chugo et al., 2005) Our prototype has seven special wheels with actuators (Fig. 1) and a passive suspension system (Asama et al., 1995). (Fig. 2) The special wheel consists of \& twelve cylindrical free rollers and helps to generate omni-directional motion with suitable o wheel arrangement and wheel control. The passive linkage mechanism ensures that the vehicle can pass over the step smoothly when the wheel contacts the step, changing the ๊ body configuration of the vehicle. No sensors and no additional actuators are required to $\bigcirc$ pass over the non-flat ground.

Source: Bioinspiration and Robotics: Walking and Climbing Robots, Book edited by: Maki K. Habib ISBN 978-3-902613-15-8, pp. 544, I-Tech, Vienna, Austria, EU, September 2007 
Many mobile vehicles which have passive linkages have been developed. (Stone, 1996; Volpe, 1997; Kuroda, 1999; Lemon, 2004) Rocker-bogie suspension mechanism is a typical one. (Stone, 1996) For realizing high step-climbing performance, these vehicles have plural drive wheels and all drive wheels are grounded by the change of body configuration for increasing traction force. However, according to the mechanical design of passive linkages, the body configuration cannot fit the terrain surface and the drive wheels float from the ground. (Fig. 3) As a result, the wheels cannot transmit traction force and these actions disturb the mobile performance of the vehicle.

Thus, in this paper, we propose a new design method of a passive linkage mechanism which ensures that all wheels are grounded for increasing the step-climbing performance of the vehicle. Our design method derives the position of the free joint point of linkages according to the shape of the obstacle which the vehicle passes over. Our key ideas are two topics. One topic is the assumption that the upward moment of the vehicle body which contacts the obstacle is required in order to pass over it with the stable posture. The other topic is the design method of the free joint point position for obtaining the upward moment.

This paper is organized as follows: we discuss the stability condition of the vehicle during step climbing in section 2; we propose the new mechanical design scheme for a passive linkage mechanism in section 3; we show the results of experiments using our prototype in section 4; section 5 is conclusion of this paper.

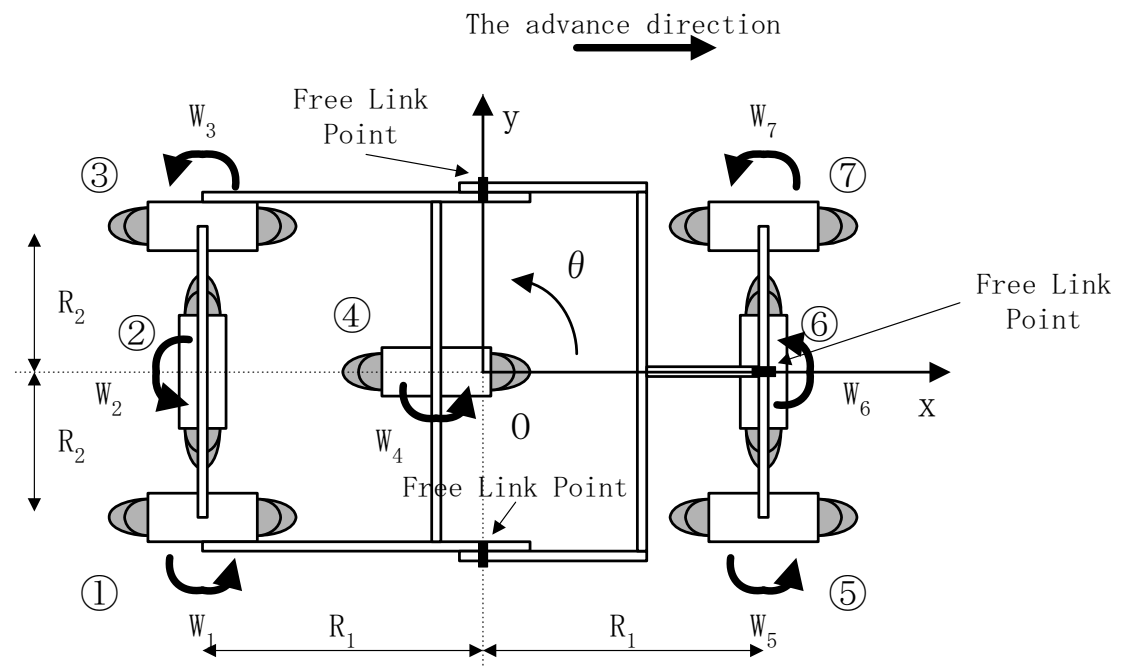

Figure 1. Our holonomic omni-directional vehicle with step-climbing ability 


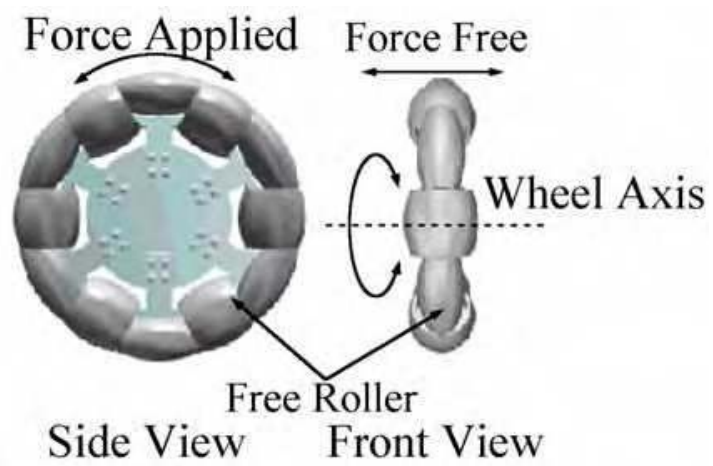

Figure 2. Special Wheels

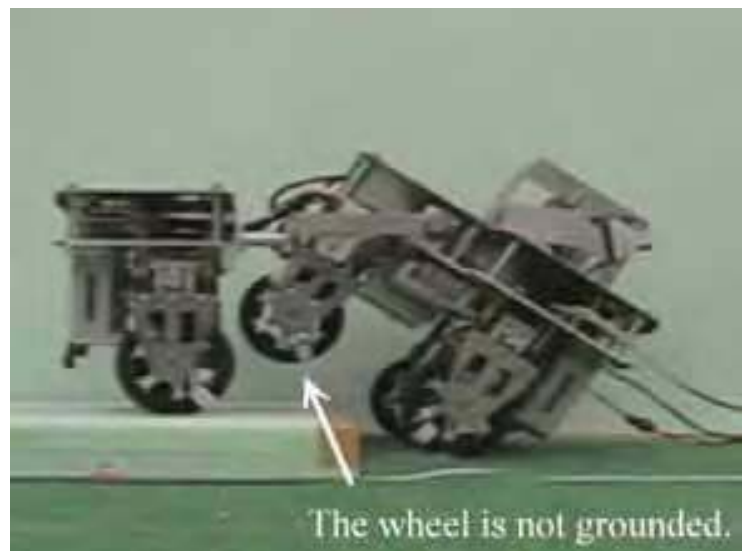

Figure 3. Off balance situation

\section{Stability Condition of Passive Linkages}

\subsection{Stability Condition}

When the vehicle passes over the step, moment forces are generated as shown in Fig. 4.

Fig. 4 (a) shows the vehicle model as it runs over the step in forward direction and Fig. 4 (b) shows the model in backward direction. The parameters are as follows;

- $l_{1}, l_{2}$ : Distances between wheels

- $m_{l}, m_{b}$ : Mass of each body

- $\quad M_{l}, M_{b}$ : Moment forces of the vehicle body ( $M_{l}$ is the rocker part and the bogie part.) when the vehicle contacts the step in forward direction

- $M_{l}^{\prime}, M_{b}^{\prime}$ : Moment forces of each body in backward direction

- $r$ : Radius of wheel

- $\quad g$ : Gravitational acceleration

- $\quad \alpha$ : Vertical angle of step (In this case, we assume a step and $\alpha=\pi / 2$.) 
- $\quad \mu_{1}, \mu_{2}$ : Friction coefficients between the wheel and step/floor

- $f_{0}, f_{1}$ : Reaction forces between the front wheel and step/floor

- $F_{0}, F_{1}$ : Traction forces between the front wheel and step/floor

- $f_{2}, f_{3}$ : Reaction forces between the front wheel/middle wheel and floor

- $F_{2}, F_{3}$ : Traction forces between the front wheel/middle wheel and floor

- $F_{4}, f_{4}$ : Reaction forces between the rocker part of the body and the bogie part

- $x_{l}, x_{b}$ : Position of the centre of gravity

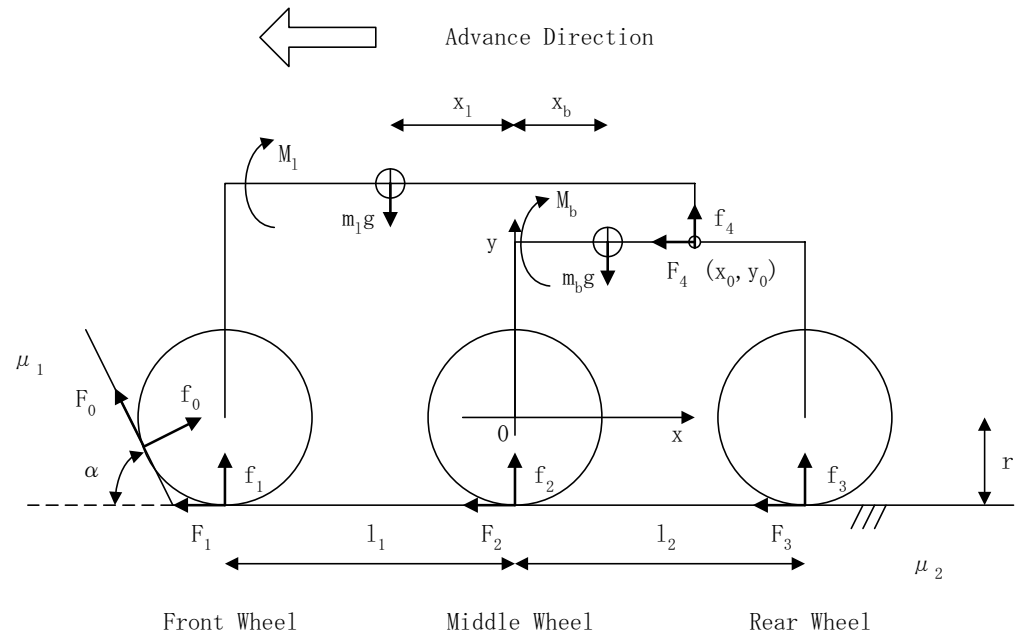

(a) Forward direction

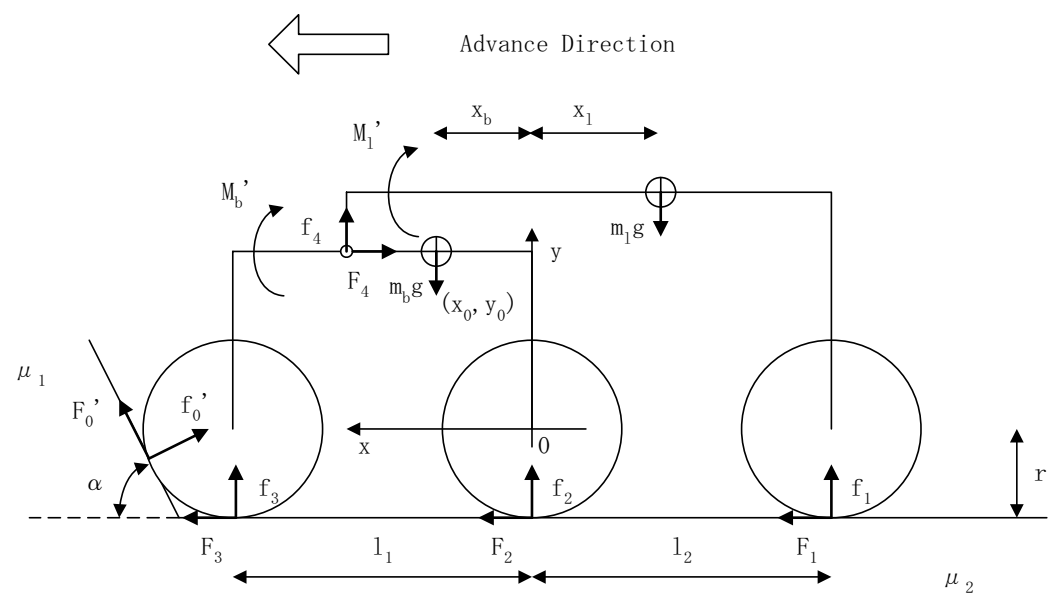

Figure 4. Moment forces

(b) Backward direction 
For realizing high step-climbing performance, the following two conditions are required.

- The traction force is enough for step climbing comparing with the mass of the body.

- When the vehicle climbs the step, the moment force of the vehicle body is positive.

If the vehicle does not have enough traction output for step climbing, the vehicle cannot pass over it. Therefore, the first condition is indispensability.

The second condition is required for that the body configuration can change according to the terrain surface and all wheels can be grounded. If all wheels with actuator are not grounded, the vehicle cannot transmit the traction force.

In this study, we assume that the vehicle has driving actuators with enough traction output and we discuss the second condition. Furthermore, for quick and efficient mobility performance, the vehicle should pass over the step in forward and backward direction. Therefore, we discuss the moment forces of both directions.

\subsection{Derivation of Moment Forces}

Now, we derive these moment forces. We set the position of free joint point as $\left(x_{0}, y_{0}\right)$ on the coordination in Fig. 4. When the vehicle contacts the $\alpha$-degree step in forward direction, these equations are derived from the balance of forces.

$$
\begin{gathered}
\left(f_{0} \sin \alpha-F_{0} \cos \alpha\right)-F_{1}-F_{4}=0 \\
\left(f_{0} \cos \alpha+F_{0} \sin \alpha\right)+f_{4}=m_{l} g \\
F_{4}-F_{2}-F_{3}=0 \\
f_{2}+f_{3}-m_{b} g-f_{4}=0
\end{gathered}
$$

From the balance of moment forces on its body, equation (5) is derived.

$$
M_{b}=f_{2} l_{2}-m_{b} g\left(l_{2}-x_{b}\right)-f_{4}\left(l_{2}-x_{0}\right)+F_{4}\left(r+y_{0}\right)=0
$$

When the vehicle climbs the step, the vehicle should have enough traction force to lift its own body. Therefore, the reaction force between the front wheel and ground is zero.

$$
f_{1}=F_{1}=0
$$

We assume that the wheel transmits maximum power to the ground within the range of friction between the wheel and ground.

$$
F_{0}=\mu_{1} f_{0}, F_{2}=\mu_{2} f_{2}, F_{3}=\mu_{2} f_{3}
$$

The moment force of rocker part of the body $\left(M_{l}\right)$ is derived as equation (8).

$$
\begin{aligned}
M_{l}= & \left(F_{0} \sin \alpha+f_{0} \cos \alpha\right)\left(r \sin \alpha+l_{1}+x_{0}\right)-m_{l} g\left(x_{l}+x_{0}\right) \\
& -f_{0}\left(\sin \alpha-\mu_{1} \cos \alpha\right)\left(r \cos \alpha+y_{0}\right)
\end{aligned}
$$

From equation (1) to (8), we can derive the equation (9) and (10). 


$$
\begin{gathered}
M_{l}=f_{0}\left(\cos \alpha+\mu_{1} \sin \alpha\right)\left(r \sin \alpha+l_{1}+x_{0}\right)-m_{l} g\left(x_{l}+x_{0}\right) \\
-f_{0}\left(\sin \alpha-\mu_{1} \cos \alpha\right)\left(r \cos \alpha+y_{0}\right) \\
f_{0}=\frac{\mu_{2}\left(m_{l}+m_{b}\right) g}{\left(\sin \alpha-\mu_{1} \cos \alpha\right)+\mu_{2}\left(\cos \alpha+\mu_{1} \sin \alpha\right)}
\end{gathered}
$$

From equation (9) and (10), the moment force when the vehicle passes over the step $(\alpha=\pi / 2)$ in forward direction are expressed as equation (11). From this equation, the moment force $M_{l}$ is function of free joint point position $\left(x_{0}, y_{0}\right)$.

$$
\begin{gathered}
\left\{\mu_{1} \mu_{2}\left(2 m_{l}+m_{b}\right)-m_{l}\right\} x_{0}-\mu_{2}\left(m_{l}+m_{b}\right) y_{0} \\
M_{l}=\frac{+\left\{\mu_{1} \mu_{2}\left(m_{l}+m_{b}\right)\left(r+l_{1}\right)-\left(1-\mu_{1} \mu_{2}\right) m_{l} x_{l}\right\}}{1+\mu_{1} \mu_{2}} g
\end{gathered}
$$

Similarly, when the vehicle passes over the step in backward direction, the moment force $M_{b}^{\prime}$ is derived as equation (12). The moment force $M_{b}^{\prime}$ is derived from the position of free joint point $\left(x_{0}, y_{0}\right)$ as $M_{l}$.

$$
\begin{gathered}
, \quad\left\{\mu_{1} \mu_{2}\left(m_{l}+2 m_{b}\right)-m_{b}\right\} x_{0}-\mu_{2}\left(m_{l}+m_{b}\right) y_{0} \\
M_{b}^{\prime}=\frac{+\left\{\mu_{1} \mu_{2}\left(m_{l}+m_{b}\right)\left(r+l_{2}\right)-\left(1-\mu_{1} \mu_{2}\right) m_{b} x_{b}\right\}}{1+\mu_{1} \mu_{2}} g
\end{gathered}
$$

From these equations, it is required to design the position of free joint point $\left(x_{0}, y_{0}\right)$ for increasing the step-climbing performance of the vehicle.

\section{Design of Passive Linkages}

\subsection{Free Joint Position}

In this section, we design the proposed passive linkage mechanism. For increasing mobile performance on the step, the moment force which applies to the vehicle body should be positive. From equation (11) and (12), the moment force when the vehicle passes over the step is led by only the position of free joint point. Thus, we design the free joint point position so that the moment force is positive when the vehicle climbs the step.

Fig. 5 shows the moment force when the vehicle contacts the step. In Fig. 5, (a) shows the moment force based on $x_{0}$ as a variable and (b) is based on $y_{0} . M_{l}$ is the moment force which is applied on the vehicle body when the vehicle passes over the step in forward direction. On the other hand, $M_{b}^{\prime}$ is the moment force when the vehicle passes over it in backward direction. The parameters of the vehicle are chosen from the prototype vehicle model as shown in Table 1. The friction coefficients between the wheel and the floor are set as $\mu_{1}=\mu_{2}=0.3$ or $\mu_{1}=\mu_{2}=0.5$. The former assumes a linoleum floor and the latter assumes a skidding on the floor. 


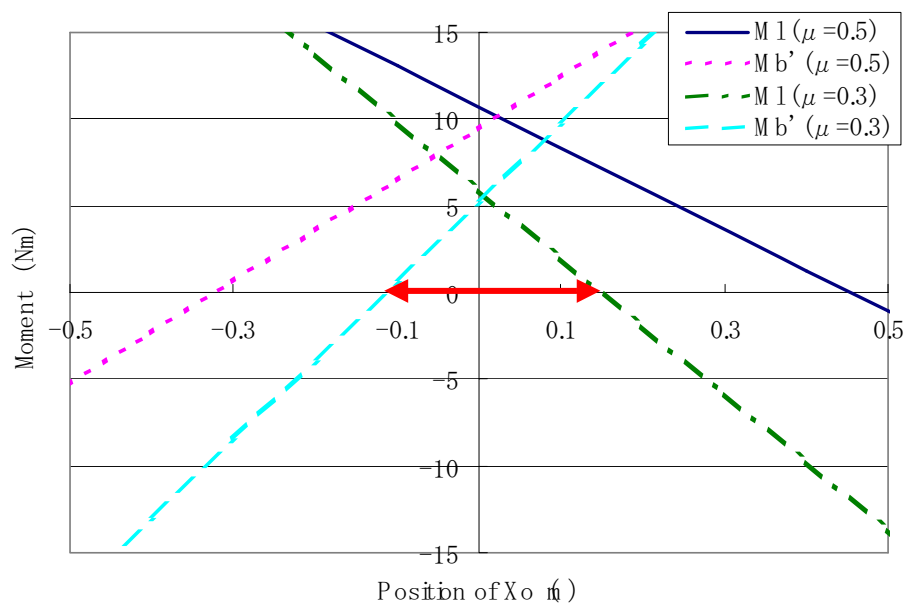

(a) Case1: $x_{0}$ is variable

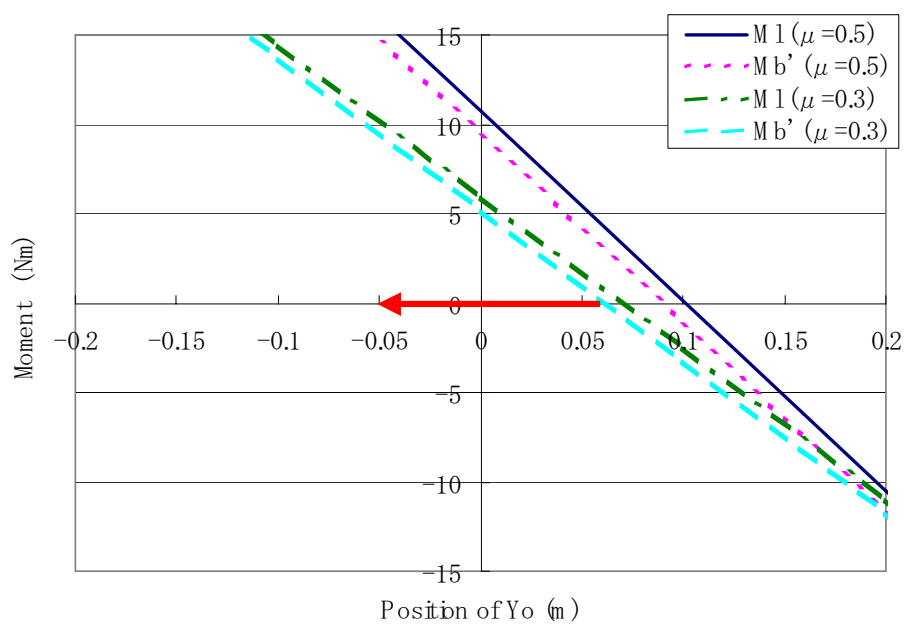

(b) Case2: $y_{0}$ is variable

Figure 5. Moment Forces when the Vehicle Climbs the Step

\begin{tabular}{|c|c|c|}
\hline & Rocker-Part & Bogie-Part \\
\hline Friction coefficient $\left(\mu_{1}, \mu_{2}\right)$ & \multicolumn{2}{|l|}{0.5 or 0.3} \\
\hline Body Weight $\left(m_{l}, m_{b}\right)$ & 13(kg) include Payload & $14(\mathrm{~kg})$ \\
\hline Wheel Diameter $(r)$ & \multicolumn{2}{|l|}{$0.132(\mathrm{~m})$} \\
\hline Distance between wheels $\left(l_{1}, l_{2}\right)$ & $0.255(\mathrm{~m})$ & $0.215(\mathrm{~m})$ \\
\hline Center-of-gravity position $\left(x_{l}, x_{b}\right)$ & $0.128(\mathrm{~m})$ & $0.108(\mathrm{~m})$ \\
\hline
\end{tabular}

Table 1. Vehicle Parameters 
From Fig. 5, the position of free joint point $\left(x_{0}, y_{0}\right)$ should meet the following requirements.

- $\quad x_{0}$ should be smaller than $0.15[\mathrm{~m}]$ and larger than $-0.1[\mathrm{~m}]$. (In the range of the arrow.)

- $y_{0}$ should be as smaller than $0.05[\mathrm{~m}]$. (However, there is danger of conflict between the vehicle body and ground if $y_{0}$ is too small.)

From two conditions, we set the free joint point as equation (13).

$$
x_{0}=y_{0}=0
$$

We propose new passive linkage mechanism as shown in Fig. 6 (b). Fig. 6 (a) is an old prototype which has rocker-bogie suspension mechanism.

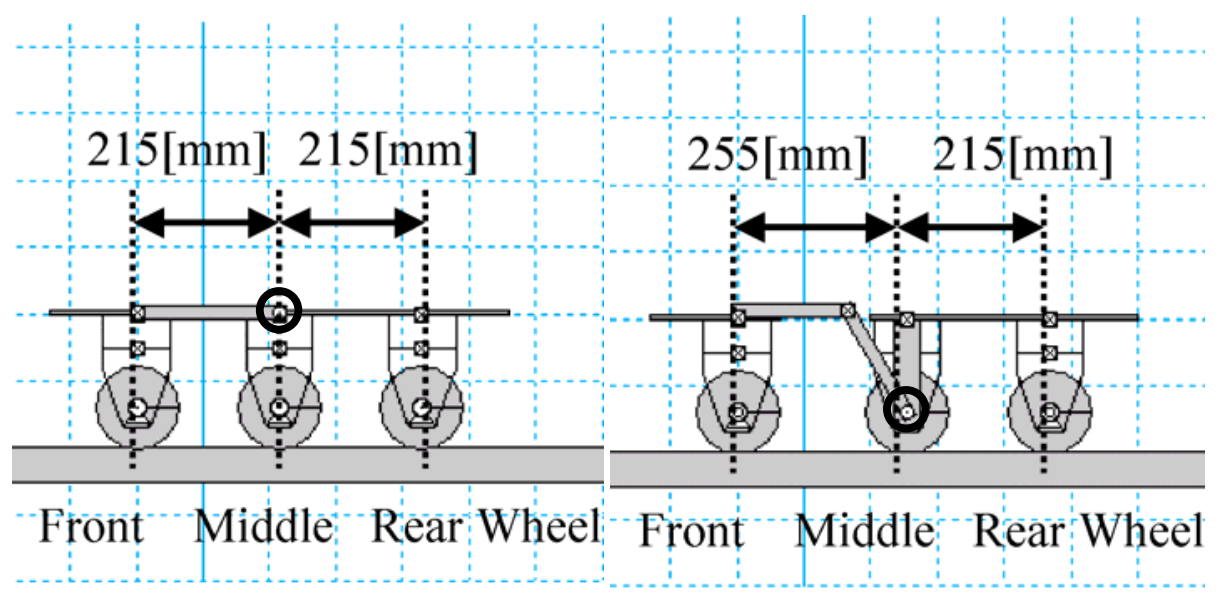

(a) Rocker-bogie Model

(b) Proposed Model

$\mathbf{O}$ is the position of a free joint point of passive linkages.

Figure 6. Passive Linkage Mechanism

\subsection{Computer Simulations}

We verify the effectiveness of our proposed design on passive linkage mechanism. In this simulation, the vehicle model passes over the step in forward direction at $0.25[\mathrm{~m} / \mathrm{s}]$ and we measure the moment force which is applied on the body when the vehicle contacts the step. We compare the result of proposed mechanism with the result of rocker-bogie mechanism. As initial conditions, simulation parameters of test vehicle model are chosen from our prototype model. Parameters are shown in table 1.

As the results of the simulation, the moment forces on the proposed mechanism are positive and all wheels are grounded during step-climbing. On the other hand, the moment forces on the rocker-bogie suspension mechanism are negative and during step-climbing, the middle wheel floats from the terrain surface. Furthermore, the step-climbing performance of the vehicle with our proposed mechanism is improved. From these results, our design for passive linkage mechanism is useful for increasing the mobile performance. 


\begin{tabular}{|r|c|r|r|r|}
\hline & \multicolumn{3}{|c|}{ Rocker-Bogie model } & \multicolumn{3}{c|}{ Proposed model } \\
\hline Height $(\mathrm{mm})$ & Results & Moment Force $(\mathrm{N}-\mathrm{m})$ & Results & Moment Force (N-m) \\
\hline 40 & Success1 & -0.006 & Success1 & 0.037 \\
\hline 60 & Success2 & -0.105 & Success1 & 0.059 \\
\hline 80 & Success2 & -0.111 & Success1 & 0.105 \\
\hline 100 & Failure & -0.129 & Success1 & 0.105 \\
\hline 150 & Failure & -0.129 & Success1 & 0.105 \\
\hline \multicolumn{5}{c}{$\begin{array}{c}\text { Success1: Success in step-climbin; } \\
\text { Success2: Success, but the middle wheel is not grounded. }\end{array}$} \\
\hline \multicolumn{5}{c}{ Failure: Failure in step-climbing }
\end{tabular}

Table 2. Simulation Results

\section{Experiments}

\subsection{Prototype}

Fig. 7 shows our prototype vehicle system (Chugo et al., 2005). The vehicle has seven wheels and each wheel is connected to a single DC motor. The size of prototype vehicle is $750[\mathrm{~mm}]$ (Length) $\times 540[\mathrm{~mm}]($ Width $) \times 520[\mathrm{~mm}]($ Height $)$ and its weight is $22[\mathrm{~kg}]$ including batteries. Detailed parameters are shown in Table 1.

The mobile mechanism consists of seven special wheels with free rollers and a passive linkage system. The free joint point of passive linkage mechanism is changeable. The special wheel (Fig. 2) realizes to generate the omni-directional motion using plural wheels arranged in the different direction and suitable wheel control (Ichikawa, 1995).

In this experiment, we change the free joint point position of passive linkage as Fig. 8. Fig. 8 (a) is rocker-bogie mode and Fig.8 (b) is our proposed mode.

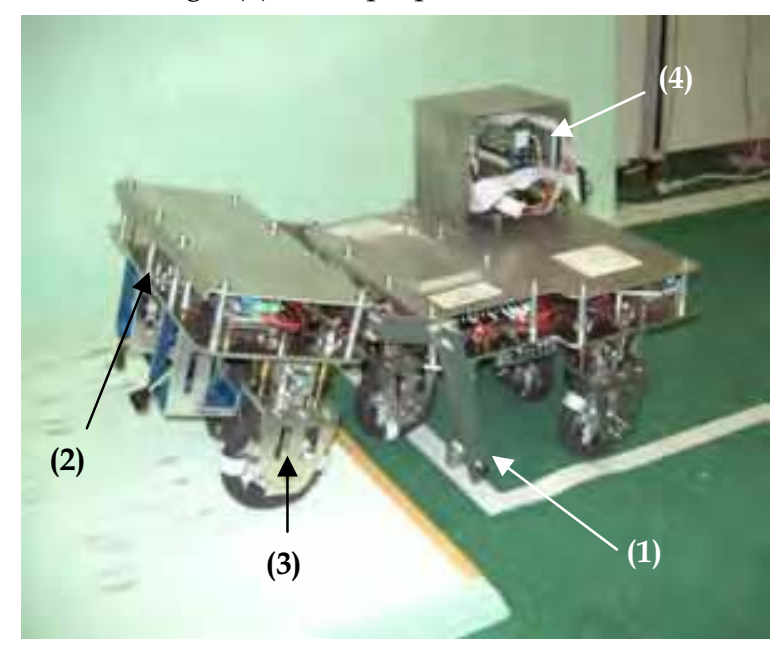

(1) and (2) are passive joints, (3) is motored wheel and

Figure 7. Our Prototype

(4) is control computer system (CPU and I/O card). 
Our prototype vehicle drives all wheels and has redundant actuations. Therefore, the vehicle system calculates from its reference speed to the actuator velocity commands based on its kinematic model using control computer system on its body (Chugo et.al., 2007).

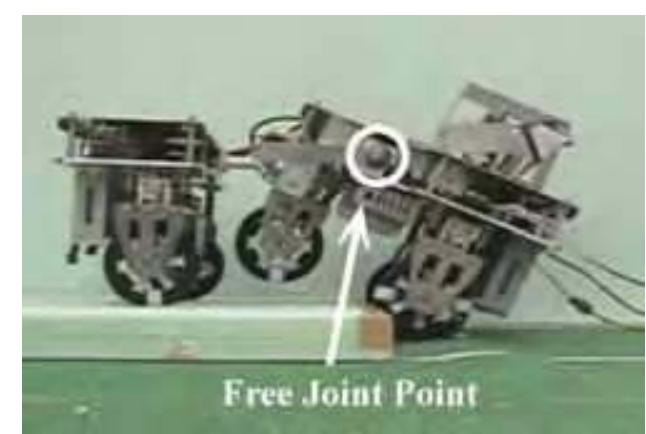

(a) Rocker-bogie Mode

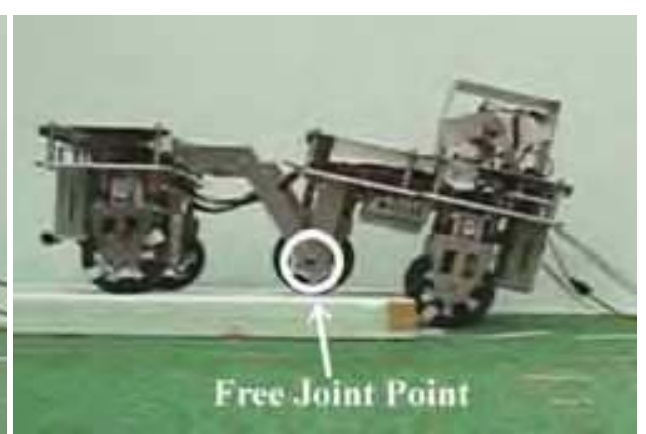

(b) Proposed Mode

Figure 8. Prototypes with Each Passive Linkage Mechanism

\subsection{Experiments}

In this experiment, the test vehicle passes over the $60[\mathrm{~mm}]$-height step in forward direction at $0.25[\mathrm{~m} / \mathrm{s}]$ and we verify the tracks of wheels. We compare the result of proposed mechanism with one of the rocker-bogie suspension mechanism. In both cases, PID based controller for traction control is employed.

Fig. 9 shows the tracks of free joint point of the vehicle during step climbing. Tracks are plotted at every $0.3[\mathrm{sec}]$. The vehicle with our proposed mechanism can pass over the step more smoothly as shown in Fig. 9. In this experiments, the vehicle with rocker-bogie suspension mechanism floats the middle wheel for 2.8[sec] as Fig. 10. On the other hand, the vehicle with our proposed passive linkage mechanism floats the middle wheel for $0.6[\mathrm{sec}]$.

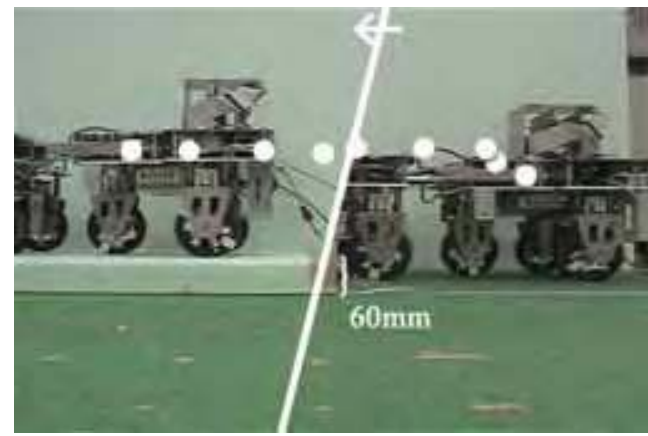

(a) Rocker-bogie Model

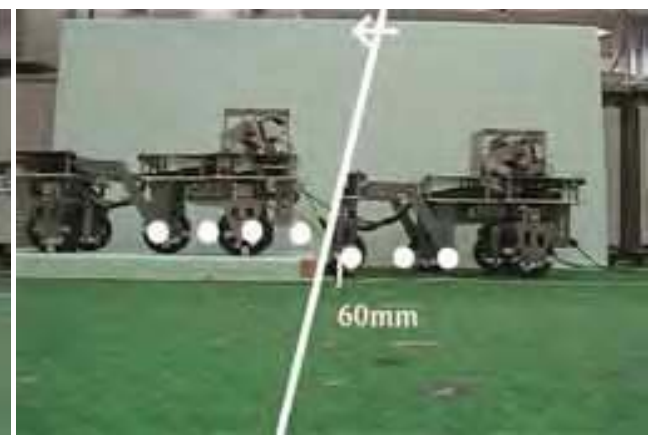

(b) Proposed Model

Figure 9. Experimental Results 


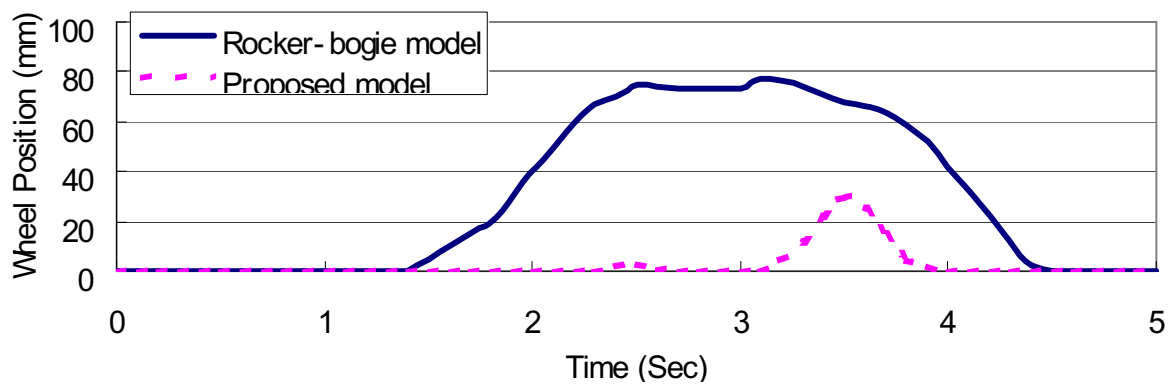

Figure 10. Tracks of Free Joint Point

As the result, the vehicle with proposed mechanism can pass over the $128[\mathrm{~mm}]$-height step maximum. The vehicle with rocker-bogie suspension mechanism can climb up only $60[\mathrm{~mm}]-$ height step. From these results, we verify that our mechanism design is effective for increasing the mobile performance of the vehicle.

\section{Conclusion}

In this paper, we proposed the mechanical design for passive linkages. We discuss the moment force which is applied on the vehicle body when the vehicle contacts the step and we derive the moment force using the position of free joint point. From the derivation, we design new passive linkage mechanism and utilize it to our prototype.

We verified the effectiveness of our proposed design on passive linkages by computer simulations and experiments. Utilizing our proposed mechanical design on the prototype, the moment force becomes positive, all wheels are grounded and step-climbing ability increases. From these results, our proposed mechanical design for passive linkages improves the mobile performance.

\section{References}

Campion, G.; Bastin, G. \& Andrea-Novel, B. D. (1996). Structural Properties and Classification of Kinematic and Dynamic Models of Wheeled Mobile Robots. IEEE Trans. on Robotics and Automation, Vol.12, No.1, (1997) pp.47-62

Bicchi, A.; Christensen, H. \& Prattichizzo, D. (2003). Motion planning and control problems for underactuated robots. Control Problems in Robotics, vol 4, Springer Tracts in Advanced Robotics, (2003) pp.59-74

Hardarson, F. (1997). Locomotion for difficult terrain. Technical Report TRITA-MMK 1997 Dept. of Machine Design, Royal Institute of Technology, (1997) pp. 1100-1179

Endo, G. \& Hirose, S. (1998). Study on Roller-Walker (system integration and basic experiments). Proc. of IEEE Int. Conf. on Robotics and Automation, (1999) pp.2032-2037

Wada, M. \& Asada, H. (1999). Design and control of a variable footprint mechanism for holonomicomnidirectional vehicles and its application to wheelchairs. IEEE Trans. on Robotics and Automation, Vol.15, No.6, (1999) pp.978-989 
Damoto, R. \& Hirose, S. (2002). Development of Holonomic Omnidirectional Vehicle "Vuton-II" with Omni-Discs. J. of Robotics and Mechatronics, Vol.14, No.2, (2002) pp.186-192

Chugo, D. ; Kawabata, K.; Kaetsu, H.; Asama, H. \& Mishima, T. (2005). Development of a Control System for an Omni directional Vehicle with Step-Climbing Ability. Advanced Robotics, Vol.19, No.1, (2005) pp.51-71

Chugo, D. ; Kawabata, K.; Kaetsu, H.; Asama, H. \& Mishima, T. (2007). Configuration-Based Wheel Control for Step-Climbing Vehicle. J. of Robotics and Mechatoronics, Vol.19, No.1, (2007) pp.52-59

Asama, H.; Sato, M.; Bogoni, L.; Kaetsu, H.; Mitsumoto, A. \& Endo, I. (1995). Development of an omni-directional mobile robot with 3 DOF decoupling drive mechanism. Proc. of IEEE Int. Conf. on Robotics and Automation, (1995) pp.1925-1930

Stone, H. W. (1996). Mars Pathfinder Microrover: A Low-Cost, Low-Power Spacecraft. Proc. of 1996 AIAA Forum on Advanced Developments in Space Robotics, (1996)

Volpe, R.; Balaram, J.; Ohm, T, \& Ivlev, R. (1997). Rocky-7: a next generation Mars rover prototype. Advanced Robotics, Vol.11, No.4, (1997) pp.341-358

Kuroda Y.; Kondo, K.; Nakamura, K.; Kunii, Y. \& Kubota, T. (1999). Low Power Mobility System for Micro Planetary Rover Micro5. Proc. of 5th Int. Symp. on Artificial Intelligence, Robotics and Automation in Space, (1999) pp.77-82

Lamon, P.; Krebs, A.; Lauria, M.; Shooter, S. \& Siegwart, R. (2004). Wheel torque control for a rough terrain rover. Proc. of IEEE Int. Conf. on Robotics and Automation, (1995) pp.4682-4687

Ichikawa, M. (1995). Wheel arrangements for Wheeled Vehicle. J. of the Robotics Society of Japan, Vol.13, No.1, (1995) pp.107-112 


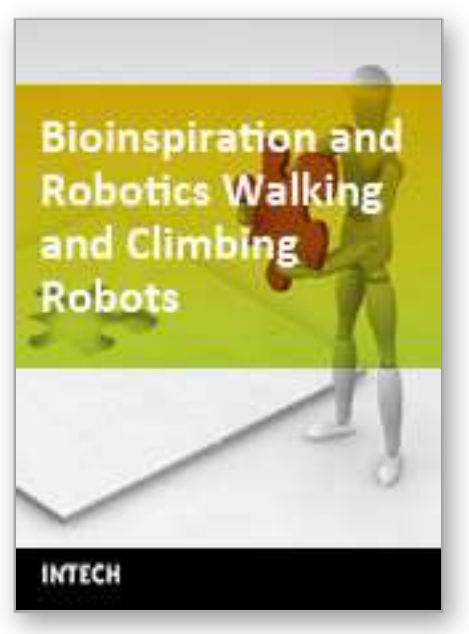

\section{Bioinspiration and Robotics Walking and Climbing Robots \\ Edited by Maki K. Habib}

ISBN 978-3-902613-15-8

Hard cover, 544 pages

Publisher I-Tech Education and Publishing

Published online 01, September, 2007

Published in print edition September, 2007

Nature has always been a source of inspiration and ideas for the robotics community. New solutions and technologies are required and hence this book is coming out to address and deal with the main challenges facing walking and climbing robots, and contributes with innovative solutions, designs, technologies and techniques. This book reports on the state of the art research and development findings and results. The content of the book has been structured into 5 technical research sections with total of 30 chapters written by well recognized researchers worldwide.

\section{How to reference}

In order to correctly reference this scholarly work, feel free to copy and paste the following:

Daisuke Chugo, Kuniaki Kawabata, Hayato Kaetsu, Hajime Asama and Taketoshi Mishima (2007). Mechanical Design of Step-Climbing Vehicle with Passive Linkages, Bioinspiration and Robotics Walking and Climbing Robots, Maki K. Habib (Ed.), ISBN: 978-3-902613-15-8, InTech, Available from:

http://www.intechopen.com/books/bioinspiration_and_robotics_walking_and_climbing_robots/mechanical_desi gn_of_step-climbing_vehicle_with_passive_linkages

\section{INTECH}

open science | open minds

\author{
InTech Europe \\ University Campus STeP Ri \\ Slavka Krautzeka 83/A \\ 51000 Rijeka, Croatia \\ Phone: +385 (51) 770447 \\ Fax: +385 (51) 686166 \\ www.intechopen.com
}

\author{
InTech China \\ Unit 405, Office Block, Hotel Equatorial Shanghai \\ No.65, Yan An Road (West), Shanghai, 200040, China \\ 中国上海市延安西路65号上海国际贵都大饭店办公楼 405 单元 \\ Phone: +86-21-62489820 \\ Fax: $+86-21-62489821$
}


(C) 2007 The Author(s). Licensee IntechOpen. This chapter is distributed under the terms of the Creative Commons Attribution-NonCommercial-ShareAlike-3.0 License, which permits use, distribution and reproduction for non-commercial purposes, provided the original is properly cited and derivative works building on this content are distributed under the same license. 